\title{
Coastal storm damage reduction program in Salerno Province after the winter 2008 storms
}

\author{
G. Benassai ${ }^{1}$, P. Celentano ${ }^{2}$ \& F. Sessa ${ }^{3}$ \\ ${ }^{I}$ Department of Applied Sciences, University of Naples Parthenope, Italy \\ ${ }^{2}$ Coastal Risk, University of Naples Parthenope, Italy \\ ${ }^{3}$ Province of Salerno, Coastal Risk, \\ University of Naples Parthenope, Italy
}

\begin{abstract}
In this paper the coastal protection system of the inhabited coastline near the city of Salerno, designed by the Salerno Province, is discussed. This low urbanized coastline, which has already suffered serious erosion over the last 40 years, had a lot of damage due to the storms of the winter of 2008: inundation of the roadways, vertical beach loss, generalized scour around bulkheads, overwash of infrastructures and recreational facilities.

These huge amounts of damage induced the design of an extensive defence project on the whole inhabited coastline of Salerno, with advanced technologies of beach nourishment, in order to assure flood damage reduction and environmental sustainability.

After analysis of the long-term erosion of the coastal site, the procedure for the choice of the coastal protection works is reported here in some detail. The description of the coastal protection system follows, which consists mainly of a long series of parallel submerged breakwaters in order to reduce the storm wave impact on the most exposed infrastructures (roads, buildings, seawater facilities). The proposed intervention takes into account the suggestions of the international EU projects "Eurosion", "Beachmed" and "Messina".
\end{abstract}

Keywords: beach erosion, coastal protection works.

\section{Introduction}

Beach erosion of the whole Mediterranean coastline is becoming of increasing importance, involving serious environmental and socio-economic consequences. 
The accretion of sandy coastlines had an inversion from the second half of the last century, with a gradual retreat that accelerated in the last two decades.

In the Salerno province the phenomenon is critical mainly in the inhabited coastline near the city of Salerno, where the damage due to both long term and seasonal erosion reached the highest values. These low urbanized coastlines, which already suffered serious erosion in the last 40 years, had a lot of damage in the winter 2008 storms. The situation is even more serious due to the absence of beach protection works in many areas and due to buildings that have now reached the coastline or are protected by a vertical wall without any defence work (fig. 1).

\section{Long-term erosion in the Salerno inhabited coastal zone}

The inhabited coastline near the city of Salerno is one of the most critical littorals of the whole province, because the beach retreat threatens the urbanized coastal zone. The statistical analysis implemented by ISPRA (formerly APAT) on the erosion of the Italian littorals, based on the comparison between the 1954 and 1998 coastline data, shows that the erosive trend is between 20 and $50 \mathrm{~m}$ in 50 years, which is a strong value if compared with the average beach depth still remained, which is at most $40 \mathrm{~m}$ (fig. 2). Moreover, the last severe storms (December 1999, December 2004, December 2008) increased the erosive trend with marine inundation of large littoral zones, including the state road n. 175 and several recreational facilities.

\section{Wave climate, beach characteristics and littoral dynamics}

The results of the coastal engineering study have demonstrated that the highest and more frequent waves come from the west and south-west. In particular, the

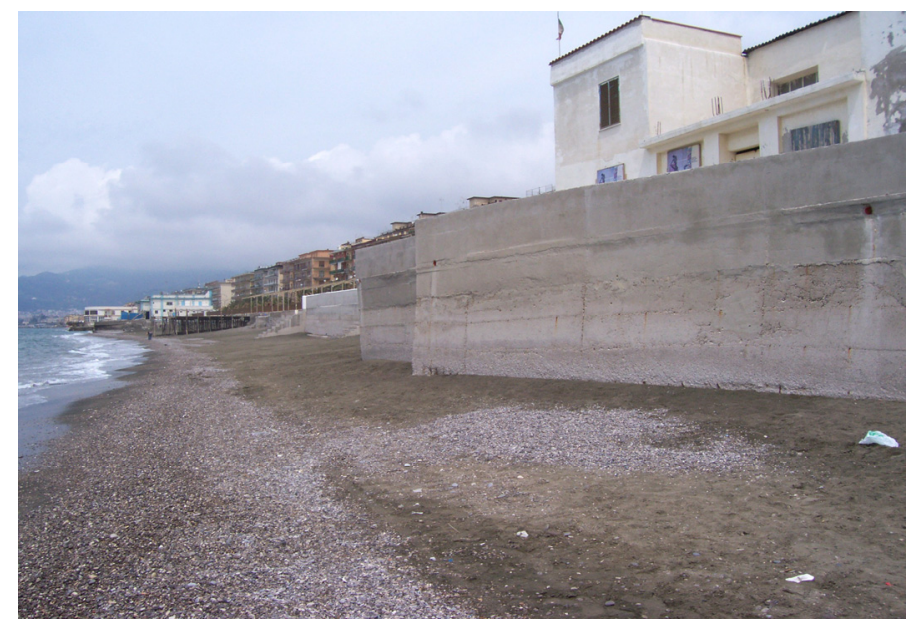

Figure 1: $\quad$ Salerno inhabited coastline protected by a vertical wall without any defence work. 


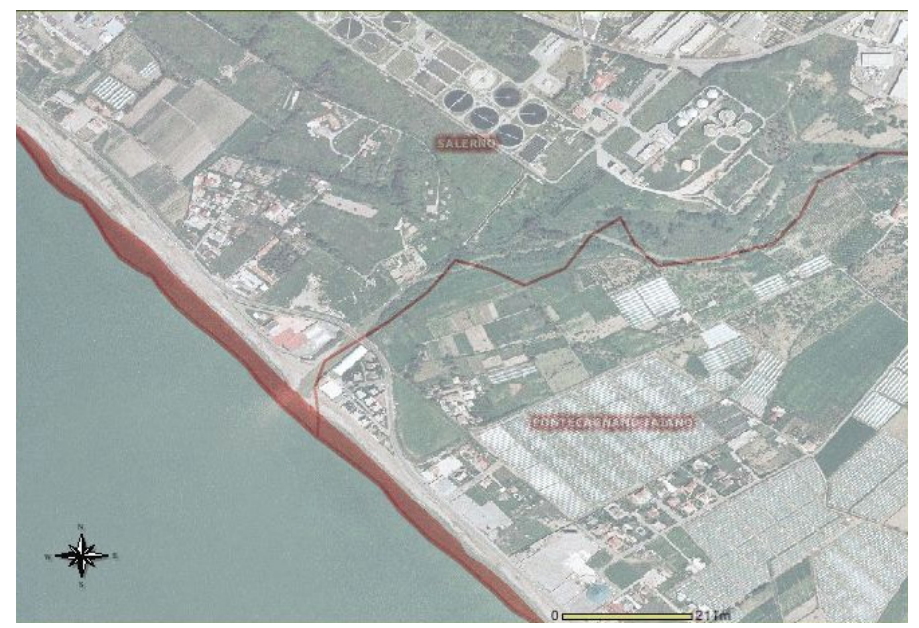

Figure 2: Long-term erosion of the Salerno coastline (the lost beach area is shown in dark grey).

Table 1: $\quad$ Sediment characteristics at the mouth of river Irno, Salerno.

\begin{tabular}{|c|c|c|c|c|c|c|}
\hline & sample & depth & $\mathbf{D}_{\mathbf{5 0}}(\mathbf{m m})$ & St. Dev. & Skewness & kurtosis \\
\hline 1 & 0 & 0.891 & 0.187 & -0.175 & 0.583 \\
\hline 2 & 1.0 & 0.199 & 0.580 & -0.269 & 1.243 \\
\hline 3 & 2.0 & 0.196 & 0.636 & -0.127 & 1.200 \\
\hline 4 & 2.8 & 0.164 & 0.609 & -0.032 & 1.270 \\
\hline 5 & 4.0 & 0.087 & 0.519 & -0.031 & 0.804 \\
\hline 7 & 5.1 & 0.126 & 0.680 & 0.141 & 0.986 \\
\hline 8 & 6.0 & 0.140 & 0.708 & 0.118 & 1.168 \\
\hline 9 & 7.0 & 0.136 & 0.725 & 0.195 & 1.019 \\
\hline
\end{tabular}

extreme waves with a return period of 50 years coming between $210^{\circ} \mathrm{N}$ and $260^{\circ} \mathrm{N}$ have values between 6.0 and $7.0 \mathrm{~m}$, while the ones coming between $160^{\circ} \mathrm{N}$ and $210^{\circ} \mathrm{N}$ are lower than $4.0 \mathrm{~m}$.

The sediment analysis showed that the emerged beach is formed by gross sand with $\mathrm{D}_{50}$ of approx $1 \mathrm{~mm}$ and lower, while the submerged beach evidences finer sediments, with $\mathrm{D}_{50}$ even lower than $0.1 \mathrm{~mm}$, as illustrated in tab. 1 by the results of the sediment analysis of the coastline offshore the mouth of the river Irno, close to the city of Salerno.

The littoral transport was calculated on the basis of the longitudinal component of the wave energy flux at the stage of breaking, starting from the inshore wave climate (frequency of sea states classified by height, period and direction).

A useful indicator of littoral stability is the Dean parameter $N_{0}$, given by:

$$
N_{0}=H_{0} / w_{f} T
$$


where:

$H_{0}=$ offshore significant wave height;

$T=$ offshore significant wave period;

$w_{f}=$ fall speed of the sand particle, given by:

$$
w_{f}=\left[\left\{\left(\rho_{s} / \rho\right)-1\right] g\right\} 0.7 D_{50} /\left(6 v^{0.4}\right) T
$$

The value assumed by $N_{0}$, called the Dean number, gives the following possibilities:

$$
\begin{array}{ccc}
N_{0}< & 2.4 & \text { very probable accretion; } \\
& N_{0}<3.2 & \text { probable accretion; } \\
N_{0} \geq 3.2 \quad & \text { probable erosion; } \\
& N_{0}>4.0 & \text { very probable erosion. }
\end{array}
$$

The $N_{0}$ value in tab 2 for the Irno coastal zone demonstrates a clear erosive tendency.

Table 2: $\quad$ Value of the Dean number for the Irno river mouth littoral.

\begin{tabular}{|c|c|c|c|c|c|}
\hline site & $D_{50}(\mathrm{~mm})$ & $w_{f}(\mathrm{~m} / \mathrm{s})$ & $H_{0}(\mathrm{~m})$ & $T_{0}(\mathrm{~s})$ & $N_{0}$ \\
\hline Irno river mouth & 0.150 & 0.0178 & 0.95 & 6.80 & 8.22 \\
\hline
\end{tabular}

\section{Main damage due to the winter 2008 storms}

In recent years, the coastline suffered from severe damage due to marine inundation of sea storms, the last of them in December 2008 and January 2009. These events also caused extensive damage along the coast, consisting in vertical beach loss of several meters, scour around bulkheads and damage to many infrastructures and recreational facilities.

This damage was due to lack of adequate building setbacks from the shoreline in combination with inadequate foundation systems of the bulkheads, so the buildings resulted extremely vulnerable to storm surge and wave-induced damage (fig. 3, fig. 4).

In some other cases, the damage was caused by lack of efficiency of the existing protection system, as in the damage of the Salerno city waterfront (fig. 5).

In this case the lack of efficiency of the breakwater located offshore the gap is evident by the comparison with the crest height and the number of the blocks of the adjacent breakwaters. Probably the higher depth of the offshore breakwater caused higher impact of the breaking waves on the armour layer, with extensive damage of the breakwater and loss of efficiency. This caused the damage to the waterfront which has been occurred only to the portion defended by this inefficient structure. 


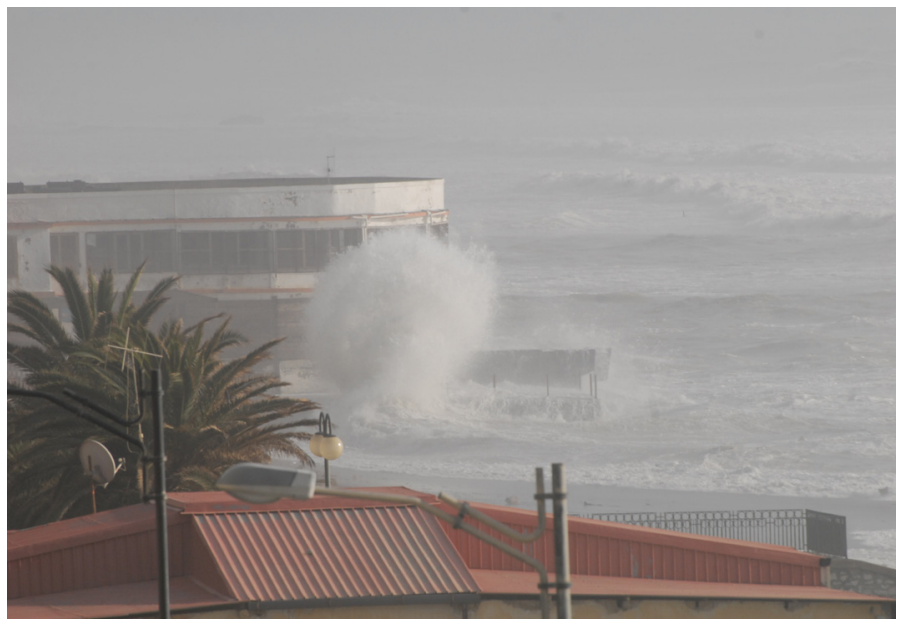

Figure 3: Storm surge and wave-induced damage to buildings during the winter 2008 storms.

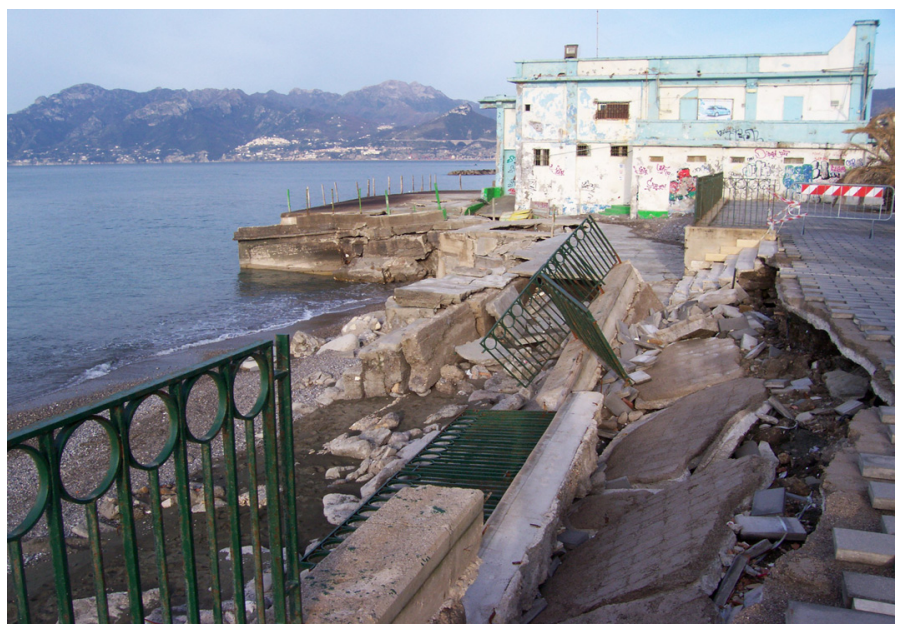

Figure 4: Damage to the waterfront of Salerno after the winter 2008 storms.

\section{The coastal protection system}

The long-term erosion and the inundation damage, which increased greatly during the winter 2008 storms, induced the Province of Salerno to design an extensive defence project on the whole inhabited coastline of Salerno, in order to assure flood damage reduction and environmental sustainability. 


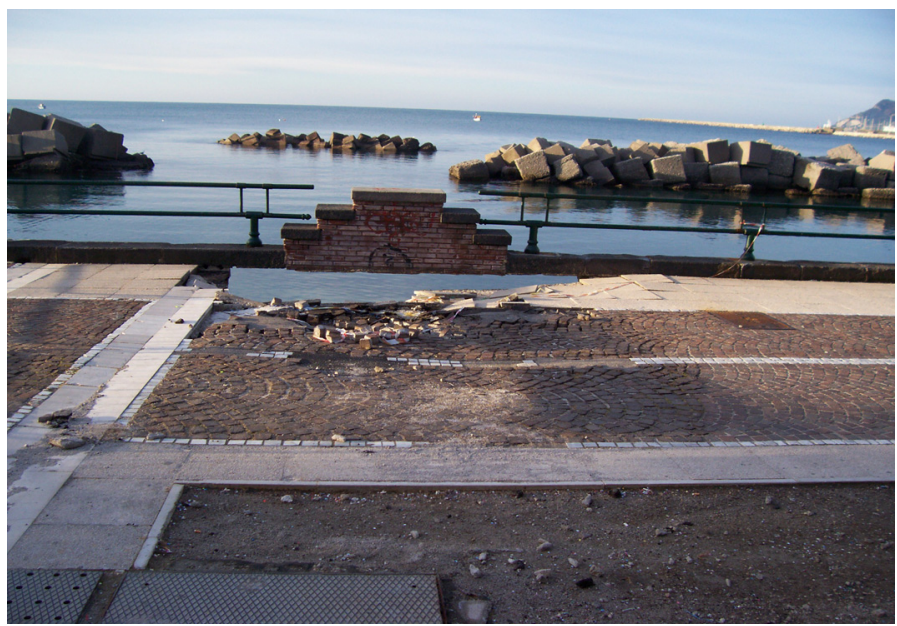

Figure 5: Damage to the waterfront of Salerno after the winter 2008 storms.

The last aspect is quite delicate, because it is known that artificial interventions often show their effects a long time after their construction, so that they often do not constitute convenient solutions for coastal protection, causing imbalance in the littoral transport between contiguous areas. Therefore the choice of the optimal intervention must be achieved through a detailed and careful study and a proper execution must consider gradual and flexible planning operations in order to reach the best solutions.

In this context the project of Salerno Province for the "interventions of defence, qualification and exploitation of the coast of the city of Salerno" is a shoreline protection system which divides the inhabited coastal zone in four parts, providing specific interventions for each of them.

The determining factors involved in the selection of the defence structures can be summed as follows:

- The purpose of the protection system in relation to urgency, efficiency and beach fruition.

- The morphology of the coastal area.

- The regime of sediment transport.

- The sea level variations and meteomarine factors.

Table 3, originally produced by Kobayashi (1987), can be useful to give a first indication of the degree of suitability for each type of intervention.

The most significant factors are the following (see Benassai [3]).

- Urgency (descending order from $a$ to $c$ ).

- Littoral transport patterns (ascending order from $d$ to $h$ ).

- Tide (ascending order from $i$ to $j$ ); the Tyrrenian Sea is enclosed in class ' $i$ '.

- Morphology of the coastal area which is linked to the dimensions of the main beach features, the height of the active beach and the erodibility of the coast (ascending order from $h$ to $l$ ). 
Table 3: $\quad$ Main factors for the choice of a beach protection system.

\begin{tabular}{|c|c|c|c|c|c|c|c|c|c|c|c|c|c|}
\hline \multirow[b]{2}{*}{$\begin{array}{l}\text { Protection } \\
\text { systems }\end{array}$} & \multicolumn{13}{|c|}{ METEOMARINE AND SOCIOECONOMIC FACTORS } \\
\hline & \multicolumn{3}{|c|}{ Urgency } & \multicolumn{5}{|c|}{$\begin{array}{l}\text { Long-shore } \\
\text { transport }\end{array}$} & \multicolumn{2}{|c|}{ Tide } & \multicolumn{3}{|c|}{$\begin{array}{l}\text { Morphologic } \\
\text { instability }\end{array}$} \\
\hline Groynes & * & 1 & 2 & 0 & 1 & 3 & 2 & 2 & 1 & 2 & 2 & 1 & * \\
\hline Det. Breakwaters & $*$ & 0 & 2 & 2 & 3 & + & 2 & + & 2 & 1 & 2 & 1 & 0 \\
\hline Beach revetment & 2 & + & * & 1 & 0 & 0 & * & $*$ & 1 & 2 & 2 & 1 & $*$ \\
\hline Nourishments & 3 & 3 & 2 & 3 & 2 & 2 & 1 & 1 & 2 & 2 & 1 & 2 & 3 \\
\hline
\end{tabular}

The degree of suitability is indicated in the following:

- 3 advisable solution;

- 2 suitable solution;

- 1 acceptable solution;

- + suitable solution for some coastal characteristics, inefficient for others;

- 0 inefficient solution;

- * unadvisable solution.

From the first column, it can be seen that a mixed protection system composed by detached breakwaters and beach fills is also suitable for a moderate urgency intervention and it can be recommended also in case of a definite littoral transport pattern. Besides, it is an advised solution in case of low or moderate morphologic instability, which is the situation of Salerno coastline.

In synthesis, the methodology illustrated in tab. 3 gives a suitable solution for artificial nourishment also in emergency conditions as an alternative to beach protection works with a greater visible impact. In fact, if the nourishment is coupled with submerged breakwaters in order to reduce the maintenance cost, it is a convenient solution even when the longshore transport is significant.

As a result of the choice, the coastal storm damage reduction program consist of a long series of parallel submerged breakwaters designed to reduce the storm wave impact on the most exposed infrastructures (roads, buildings, recreational facilities). The submerged breakwaters have been localized on depths ranging between 4 and $5 \mathrm{~m}$, at a distance between 100 and $150 \mathrm{~m}$, with beam width of approximately $12-14 \mathrm{~m}$, in order to dissipate most of the breaking wave energy.

The intensity of coastal protection, for both emerged and submerged breakwaters, depends on the relative crest height and on the distance from the shoreline. Fig. 6 gives two cases of emerged breakwaters of different length at the same distance from the shoreline. It is showed that a significant relative length (length made non-dimensional with the breaking zone width) or a too close relative distance (distance made non-dimensional in the same manner) can lead to the formation of a tombolo (fig. 6). This is the reason why the designed breakwaters are alternated with gaps and located closer to the coastline in case of need of major protection, while they can be located at a higher distance when there is no particular infrastructure to be protected (fig. 7). 
The hard measures have been coupled with beach fills refurnished by offshore marine sand, taken from the offshore submerged bars (fig. 8). These protection works ensure the necessary defence from the meteomarine factors and minimise the environmental impact. Furthermore, as the defence structures are submerged with gaps of suitable size, they ensure the necessary water circulation and periodic replacement of water, in order to avoid stagnation phenomena

The proposed intervention takes into account the suggestions of the international EU projects "Eurosion", "Beachmed" and "Messina". With reference to the first project, the intervention is classified as soft. The EU project "Beachmed" has demonstrated that this type of intervention (beach fill protected with a submerged breakwater) has proven to suffer from minor losses of borrow material, in comparison with a pure beach fill without submerged barriers.

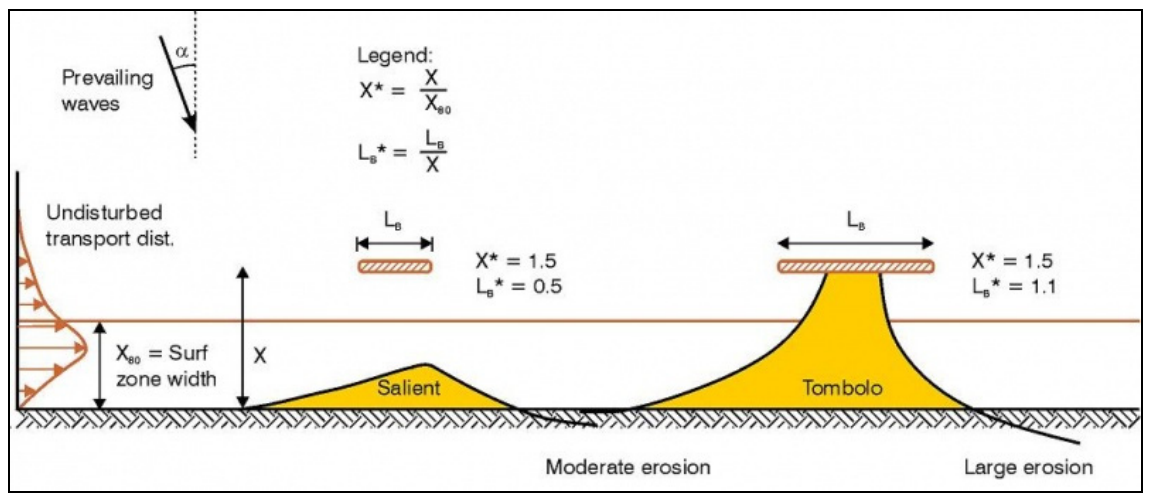

Figure 6: Intensity of protection as a function of the relative length; the same applies for the relative distance.

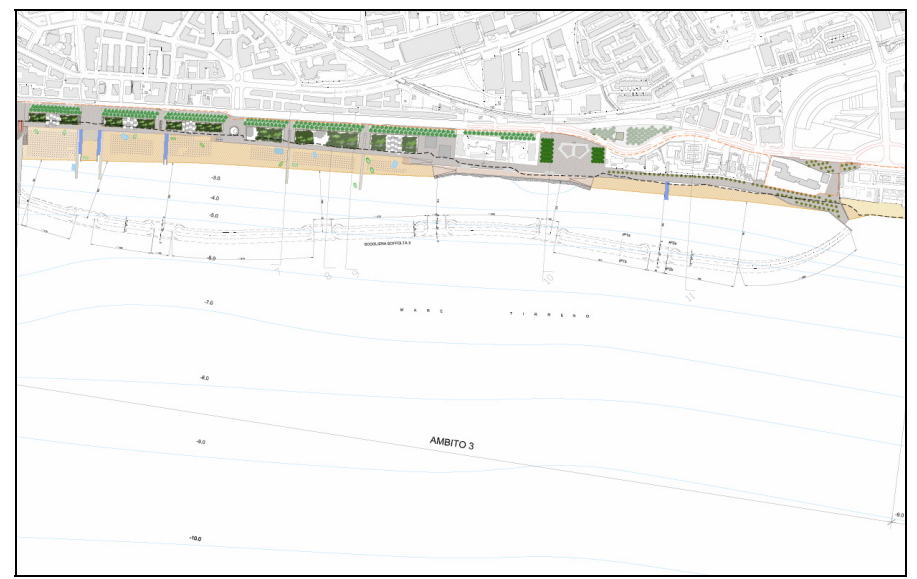

Figure 7: Plan of part of the Salerno shoreline protection works. 


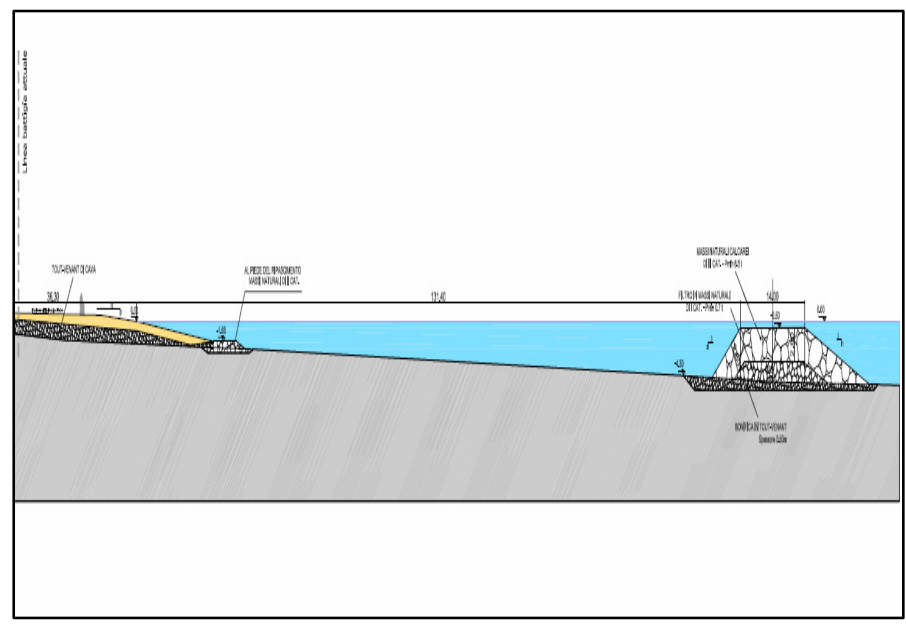

Figure 8: Profile of part of the Salerno shoreline protection works.

\section{Conclusions}

An extensive defence project on the whole inhabited coastline of Salerno, with advanced technologies of beach nourishment, has been proposed by Salerno Province in order to assure flood damage reduction and environmental sustainability. The system consists mainly of a long series of parallel submerged breakwaters in order to reduce the storm wave impact on the most exposed infrastructures (roads, buildings, seawater facilities), coupled with beach nourishment.

The choice of the coastal protection works has been justified in view of the scientific literature and of the suggestions of the international EU projects "Eurosion", "Beachmed" and "Messina".

After the project realization, planned for the next two years, an intensive monitoring program will be realized in order to verify the project efficiency in terms of beach protection and coastline advance.

\section{References}

[1] APAT, Università degli Studi di Roma Tre, 2002. Atlante delle onde nei mari italiani. Istituto Poligrafico e Zecca dello Stato.

[2] APAT, 2007. Atlante delle opere di sistemazione costiera. Manuali e Linee Guida, 44/2007, Roma.

[3] Benassai G., 2006. Introduction to coastal dynamics and shoreline protection. WIT Press, $336 \mathrm{pp}$.

[4] Provincia di Salerno (2008). Progetto di difesa e riqualificazione della costa di Salerno e di Pontecagnano (In Italian).

[5] USACE, 2002, Coastal Engineering Manual, Coastal and Hydraulics Laboratory, Vicksburg, MS. http://chl.erdc.usace.army.mil 
[6] EUrosion project, 2004: http://www.eurosion.org

[7] BEACHMED-e, 2006. Strategic Management of Beach Protection Measures for the Sustainable Development of Mediterranean coastal areas www.beachmed.eu

[8] MESSINA, 2005 Monitoring European Shorelines and Sharing Information on near shore Areas. http://www.interreg-messina.org 